\section{Luminescent Decomposition of Nitrous Oxide}

The thermal dissociation of nitrous oxide has received considerable attention in the past in connexion with the collision theory of unimolecular and bimolecular reactions ${ }^{1}$, and it is known that oxygen atoms can be produced as a result of the primary dissociation $\mathrm{N}_{2} \mathrm{O}=\mathrm{N}_{2}+\mathrm{O}$. This dissociation was considered to be the chain-initiating process in the $\mathrm{H}_{2}-\mathrm{N}_{2} \mathrm{O}$ reaction by Melville ${ }^{2}$, and in the $\mathrm{CO}-\mathrm{N}_{2} \mathrm{O}$ reaction by $\mathrm{Bawn}^{3}$. In view of the production of atomic oxygen in the decomposition of nitrous oxide, some work has been carried out on the $\mathrm{N}_{2} \mathrm{O}-\mathrm{SO}_{2}$ system in order to obtain some basic information on the association reaction $\mathrm{SO}_{2}+\mathrm{O}=\mathrm{SO}_{3}$, a process believed to be of some importance in relation to the oxidation of sulphur dioxide in flames". This work will be reported in detail elsewhere; but it is the purpose of this note to describe some observations on the nature of the luminescence accompanying the decomposition of nitrous oxide at temperatures of the order of $900^{\circ} \mathrm{C}$., and the effect of various additions on this. Zeldovitsch and Jakovlev ${ }^{5}$ have studied briefly the explosive decomposition of nitrous oxide at high temperatures, and the appearance of yellow. green flashes in the combustion of carbon in nitrous oxide at $600-800^{\circ} \mathrm{C}$. has been recorded by Shaw ${ }^{B}$ and Arthur?.

A flow method was used in which nitrous oxide was passed at a steady rate through an electrically heated quartz tube, $3 \mathrm{~cm}$. in diameter and $20 \mathrm{~cm}$. in length, at one end of which was a quartz window. The temperature of the tube was raised at a steady rate of $10^{\circ} \mathrm{C}$. a minute, and no luminescence was observed in the decomposing gas for temperatures up to $850^{\circ} \mathrm{C}$., although above $750^{\circ}$ the exit gases were tinged brown, due to the formation of oxides of nitrogen. At $850^{\circ}$ a very pale yellow-green haze was seen in the tube, and the rate of increase of temperature was reduced to $5^{\circ} \mathrm{C}$. a minute. The intensity of the glow gradually increased, and at $900^{\circ}$ a vivid luminescence was given. At a flow-rate corresponding to a time of contact of 3 sec. a series of flashes occurred, and by adjusting the rate to correspond to a time of contact of 1 sec. it was possible to maintain a steady glow of high intensity.

When 1 per cent by volume of chlorine was added, the intensity of the glow was very much reduced, and with 2 per cent chlorine the glow disappeared. On the addition of a similar quantity of sulphur dioxide the intensity of the glow was apparently unaltered, although visual observation was complicated by the formation of a dense cloud of sulphur trioxide. Formation of the latter, detected by the formation of sulphuric acid mist on bubbling the exit gases through water and simultaneous measurement of the dew-point of the exit gases ${ }^{8}$, in the $\mathrm{N}_{2} \mathrm{O}-\mathrm{SO}_{2}$ system was found to take place at temperatures so low as $550-600^{\circ}$, where the decomposition of nitrous oxide as revealed by ordinary manometric methods is exceedingly slow.

The spectrum of the glow was recorded on a Hilger medium quartz spectroscope and was found to consist of a continuum extending from the visible to the ultra-violet with a maximum intensity in the yellowgreen. With long exposures it was possible to observe faint emission bands superimposed on the continuum, and these were found to be due to nitrous oxide. In its general characteristics the glow accompanying the high-temperature dissociation of nitrous oxide is very similar to that given when nitric oxide reacts with atomic oxygen in a discharge tube, or is added to flames containing oxygen atoms; it can be attributed to the association reaction $\mathrm{NO}+\mathrm{O}=$ $\mathrm{NO}_{2}+h \nu$ (continuous), a process which has been described in detail by Gaydon ${ }^{\circ}$.

The formation of nitric oxide in the decomposition of nitrous oxide is usually considered to arise from the attack of atomic oxygen on it: $\mathrm{N}_{2} \mathrm{O}+\mathrm{O}=2 \mathrm{NO}$; although at temperatures of $900-1,000^{\circ} \mathrm{C}$. the possibility of the primary dissociation $\mathrm{N}_{2} \mathrm{O}=\mathrm{N}+\mathrm{NO}$ also arises. Both these reactions require a high energy of activation ${ }^{10}$, and sufficient nitric oxide; a visible glow with the atomic oxygen present is not given until high temperatures are attained.

British Coal Utilisation Research Association,

\section{G. Whittingham}

13 Grosvenor Gardens, London, S.W.1.

Jan. 2.

${ }^{1}$ Musgrave, F. F., and Hinshelwood, C. N., Proc. Roy. Soc., 185, 23 (1932); 187, 25 (1932).

${ }^{2}$ Melville, H. W., Proc. Roy. Soc., 142, 524 (1933).

'Bawn, C. E. H., Trans. Faraday Soc., 31, 461 (1935).

Dooley, A., and Whittingham, G., Trans. Faraday Soc., 42, 354 (1946).

S Zeldovitsch, J. B., and Jakovlev, B. I., C.R. Acad. Sci., U.S.S.R., 19, 699 (1938).

- Shaw, M. S., J. Chem. Soc., 2661 (1929).

"Arthur, J. R., private correspondence.

- Whittingham, G., Nature, 157, 550 (1946).

- Gaydon, A. G., Proc. Roy. Soc., 183, 211 (1944).

${ }^{10}$ Henriques, jun., F. C., Duncan, A. B. F., and Noyes, jun., W. A., J. Chem. Phy8., 8, 518 (1938).

\section{A Novel Method of Making Aerosols}

THE phenomena occurring when a closed vessel containing a simple liquid is heated to a temperature above the critical temperature of the liquid are well known. What happens when a solution, and more especially a solution of a substance having a very small vapour pressure, is treated in the same way is perhaps less familiar, although the findings of several investigators are on record ${ }^{1}$. In some binary systems a partial separation of the components takes place as the critical point is approached; in others, no heterogeneity can be detected even when the liquid phase has vanished. In this connexion we have made some observations in small-scale experiments in which sealed capillary tubes ( $1 \mathrm{~mm}$. bore, with thick walls) partly filled with aqueous solutions of potassium chromate were slowly heated. Even when the concentration of potassium chromate was increased to $50 \mathrm{gm}$. per $100 \mathrm{ml}$, no separation of solid occurred when the critical temperature (in this case, about $430^{\circ}$ C.) was attained, and the whole of the system passed into the vapour state, the colour of the solute becoming uniformly distributed throughout the tube. On cooling, liquefaction took place and the original solution was spontaneously re-formed.

In our view, the most remarkable feature of these events was that a refractory solid. had been completely vaporized at a temperature some $500^{\circ} \mathrm{C}$. below its melting point, and it occurred to us that this method of bringing substances of very low volatility into the vapour state might be used for the production of aerosols of these materials, provided a rapid expansion of the vapour, accompanied by dilution with air, could be arranged (cf. the formation of smokes by condensation). We therefore repeated the experiment of heating a sealed tube containing a 50 per cent solution of potassium chromate in water, 